\title{
Pós-modernidade e risco na Bacia Hidrográfica do Alto Paranapanema: a construção social da subpolítica ambiental no município de Piraju (SP)
}

\section{Post-Modernity and Risk in the Upper Basin Paranapanema: the Social Construction of Environmental Sub-Policy in the Municipality of Piraju (SP)}

\author{
José Luiz Fernandes CERVEIRA FILHO*
}

\begin{abstract}
RESUMO
Durante o século vinte, a indústria hidroelétrica foi responsável pela maior parte da oferta de energia no Brasil. Contudo, mais recentemente ela tem sido apontada como uma das grandes responsáveis pela ampliação da degradação ambiental. A partir de diversas evidências sobre danos causados ao ambiente natural, algumas localidades destinatárias desses projetos hidroelétricos passaram a refletir de maneira mais aprofundada sobre os riscos sociais e culturais intrínsecos ao desenvolvimento da matriz energética. A presença sistemática de problemas nesse campo ambiental trouxe uma possibilidade real de interferência social, via novos arranjos políticos e subpolíticos, por intermédio de novas instituições sociais, seja no âmbito federal, estadual e, até mesmo, municipal, como certos institutos jurídicos locais. Se por um lado o reconhecimento que tais atividades degradam o meio ambiente não garante que medidas serão tomadas, por outro contribui em grande medida para o desenvolvimento de novos padrões morais de sociabilidade e ações políticas. O objetivo desse artigo é o de compreender e apresentar quais foram as principais motivações sociais para que o município de Piraju (SP) elaborasse e aprovasse recentemente um conjunto de medidas altamente restritivas às atividades hidroelétricas. Também nos interessa expor como se deu o processo de construção social de um marco regulatório jurídico-reflexivo de competência municipal, e em que medida o estudo desse processo construcionista pode corroborar algumas teorias sociais contemporâneas. Através de um estudo de caso, procurou-se compreender a trajetória de um grupo local ideologicamente atado ao ideário ambientalista e como, variante desse interesse, a análise de alguns questionamentos considerados de cunho pós-modernos colaborou para a desconstrução do desenvolvimentismo no campo da hidroeletricidade.
\end{abstract}

Palavras-chave: pós-modernidade; subpolítica; energia hidroelétrica.

\footnotetext{
" Doutor em Ciências Sociais (UFSCAR). Professor Adjunto do Departamento de Ciências Sociais e do Programa de Pós-Graduação em Meio Ambiente e Desenvolvimento da Universidade Federal do Paraná (UFPR).Email: j_cerveira@terra.com.br
} 


\begin{abstract}
During the twentieth century the hydroelectric industry was responsible for most of the energy supply in Brazil. However, more recently it has been identified as responsible for a major expansion of environmental degradation. From various evidences filed on damages to the natural environment, some places that are recipients of these hydroelectric projects began to reflect more deeply about the inherent risks to the social and cultural development of the energy matrix. The presence of systematic problems in the environmental field has brought a real possibility of social interference, via new political arrangements, as well as sub-political, through new social institutions, whether federal, state and even municipal, and certain local legal institutions. On the one hand the recognition that such activities do not degrade the environment ensures that measures are taken; on the other hand, it contributes greatly to the development of new moral standards of social and political action. The aim of this paper is to understand and present what were the main social motivations for the city of Piraju (SP) to recently develop and approve a package of highly restrictive measures to hydroelectric activities. We are also interested in exposing how was the process of social construction of a legal and regulatory framework reflective of municipal jurisdiction, and to what extent the study of this constructionist process can corroborate contemporary social theories. Through a case study, we sought to understand the trajectory of a local group ideologically tied to environmental ideals, and, as a variant of this interest, the analysis of the nature of some questions contributed to postmodern deconstruction of developmentalism in the field of hydropower.
\end{abstract}

Keywords: post-modernity; sub-policy; hydropower.

\section{Introdução}

$\mathrm{Na}$ parte inicial desse artigo, pretendo fazer uma breve revisão teórica sobre a Sociologia Ambiental. Trata-se de uma compreensão preliminar sobre as suas origens e perspectivas, onde apresento as suas bases teóricas e metodológicas com o intuito de entendê-la e situá-la como uma disciplina emergente para o estudo dos problemas socioambientais. A fim de situar o campo de investigações teóricas em que se insere, discorro, inicialmente, sobre a sua vertente construcionista (HANNIGAN, 1995), como esta aborda teórica e metodologicamente os problemas socioambientais (BUTTEL, 2000), e também como, a partir desta vertente, podemos estabelecer interfaces com abordagens originadas de outros campos das ciências para o estudo dos problemas socioambientais.

Posteriormente, faço referências às teorias sociológicas contemporâneas que debatem a ontologia pós-moderna, caracterizada pelos riscos ambientais e pelas incertezas e controvérsias científicas (GUIVANT, 1998). Apresento nessa parte as principais teses e ideias de alguns dos teóricos sociais contemporâneos mais influentes (BECK, 1997; GIDDENS, 1991, 1997), pro- curando contribuir para o debate acerca de alguns de seus temas, como a modernização reflexiva, a subpolítica e a reflexividade social, por exemplo. Na parte final do artigo, apresento um conflito social envolvendo uma grande corporação do setor hidroelétrico (Companhia Brasileira de Alumínio - CBA) e um grupo de ambientalistas como um típico estudo de caso para a análise socioambiental, onde destaco os conceitos da "cultura do risco" e enfatizo o desenrolar de um controvertido projeto de aproveitamento de potencial hidroelétrico em um pequeno município do interior paulista, obstaculizado por um tipo de ação condizente com a alta modernidade: a subpolítica.

Torna-se importante destacar, inicialmente, que, mesmo já havendo no Brasil diversas demandas e questionamentos envolvendo o desenvolvimento da matriz hidrelétrica e o socioambiente, como, por exemplo, os casos envolvendo diversos agricultores no oeste dos Estados de São Paulo e, principalmente, do Paraná (o que culminou na construção do Movimento dos Atingidos por Barragens - MAB), o caso em tela não é capaz de abrigar similaridades com essa demanda. Ao contrário, assenta-se em dois movimentos sociais que estão atados ao universo daquilo que podemos chamar de hegemonia dominante, já que um grupo - os ambientalistas - é com- 
posto por indivíduos pertencentes à classe média local e o outro - os agricultores - está filiado ao Sindicato Rural Patronal, constituindo-se no oposto àquilo que poderíamos caracterizar como agricultores familiares, ou mesmo como agricultores atingidos por barragens (na expressão e no sentido laico conferido pelo MAB), mesmo tendo a questão da supressão fundiária por alagamento como mola mestra do evento.

Outro ponto que se faz necessário esclarecer assenta-se na relação desse estudo com outros entendimentos sobre a questão. Sabemos que a literatura apresenta uma larga possibilidade de ampliação da análise, por intermédio de autores da envergadura de Acselrad (2004), por temas como a justiça ambiental, por exemplo. Novamente insistimos na originalidade e na adequação desse estudo, que se propõe a analisar um movimento social oriundo da classe média local, não se caracterizando o emprego de alguns conceitos consagrados na literatura específica, mesmo compreendendo aspectos que poderiam produzir o debate. Também não pode ser o caso, dada a exiguidade do espaço para a análise. Informo que as legislações socioambientais construídas nas décadas de 1980 e 1990 estão apresentadas de acordo com o interesse que nos rege na construção desse texto, não sendo apresentadas as construções sociais desses marcos regulatórios por entendermos tergiversação para esse compêndio.

Por fim, esclareço que esse estudo é resultado de pesquisa realizada durante o curso de Doutorado na Universidade Federal de São Carlos, constituindo-se, portanto, em uma análise pormenorizada daquilo que foi produzido como resultado da tese. Para tanto, diversas entrevistas foram realizadas e a técnica instrumental de "seguir os atores" foi posta em prática, iniciando-se com a observação participante, passando pela análise de discurso e, por fim, pela análise das redes sociotécnicas que montaram o evento. Informo também que a opção metodológica pela técnica do estudo de caso impôs-se por compreender que, enquanto modelo de levantamento de dados empíricos, ela permite o acesso a informações privilegiadas e detalhadas sobre a realidade, onde os processos sociais se desenrolam concretamente e, também, por entender que um estudo de caso se caracteriza pela busca da maior profundidade possível de informações, o que permite a problematização de questões que poderiam passar despercebidas em estudos muito abrangentes.

\section{Sociologia Ambiental: um ponto de partida}

Buttel (2000) caracteriza a Sociologia Ambiental como um esforço para descobrir e resgatar a materialidade da estrutura e da vida social e, desta forma, produzir reflexões relevantes para resolver problemas ambientais. Em termos gerais, a disciplina pode ser definida como o estudo das inter-relações entre sociedade e meio ambiente. Mais precisamente, os sociólogos ambientais estariam interessados nos mecanismos específicos pelos quais a sociedade e o meio ambiente se relacionam e quais os valores culturais e as crenças que motivam as pessoas para usar o meio ambiente em um sentido particular. Esse esforço implica equacionar uma dicotomia que historicamente se estabeleceu entre as ciências sociais e o ambiente natural.

A relação entre sociologia e meio ambiente possui dois componentes fundamentais que a tornam problemática: 1) refere-se a um fato que é inerente à condição humana, qual seja, a sua duplicidade enquanto ser biológico e ser social (o ser humano, ao mesmo tempo em que é uma dentre as espécies que compõem a biosfera, é, também, um criador de ambientes singulares e socialmente distintos, o que o conduz, sob o ponto de vista das ciências, a uma relação ambivalente); 2) refere-se ao fato de que a sociologia herdou um duplo legado em relação à biologia (de um lado, o pensamento sociológico é fortemente influenciado pelas imagens da evolução dos organismos, pela utilização de conceitos trazidos da ecologia e pela adoção de posturas metodológicas das ciências naturais; de outro, o desenvolvimento da teoria sociológica segue um modelo moldado por reações contra o simplismo biológico). A origem disso estaria em que os principais teóricos da sociologia teriam deixado um legado fortemente antropocêntrico incorporado à sociologia moderna. Suas teorias caracterizaram-se pela primazia sociológica na explicação dos fenômenos sociais, resultando, com isto, um tabu implícito contra as variáveis biológicas, configurando-se em um fator limitante na expansão dos horizontes da sociologia para a compreensão das relações entre sociedade e meio ambiente.

Alonso e Costa (2002) observam uma ontologia realista entre as principais teorias sociais clássicas: elas 
teriam separado sociedade e natureza para demarcar com maior facilidade o seu campo de estudo. Isso, em certa medida, corresponde a uma das explicações propostas por Hannigan (1995), que argumenta que, durante os primórdios da sociologia, os sociólogos já procuravam compreender as limitações do determinismo na explicação do desenvolvimento e da mudança social. Contudo, isto não quer dizer que os clássicos não tenham dedicado atenção a aspectos do ambiente natural; o meio ambiente não foi algo desconhecido para os principais formuladores do conhecimento sociológico. O que ocorreu foi que o meio ambiente não foi aceito como um conceito central no desenvolvimento de suas formulações. Nesse sentido, a contemporaneidade da Sociologia Ambiental pode ser considerada, também, como uma crítica aos mestres da sociologia pela falta de atenção às bases materiais e biofísicas da existência humana e da vida social.

Quanto à sua visibilidade social, a emergência da Sociologia Ambiental está relacionada com o surgimento do movimento ambientalista, principalmente porque muitos estudos que vieram a constituir a Sociologia Ambiental desenvolveram-se a partir do interesse pelo movimento ambientalista, quando não pelo próprio ativismo de alguns sociólogos. Desta forma, a disciplina deve muito de suas características e a sua própria emergência ao clima sociointelectual no qual se desenvolveu, por volta dos anos 1960 e 1970. Outra contribuição importante para a configuração do novo campo foram os estudos oriundos da Sociologia Rural, que vinha trabalhando há décadas em pesquisas na agricultura, florestas e usos de parques, dentre muitos outros temas relacionados ao ambiente natural. Assim, os sociólogos rurais estiveram mais preparados para proceder a estudos que partissem do reconhecimento da importância da base biofísica na estruturação da sociedade. Além disso, a Sociologia Rural tem contribuído com estudos importantes sobre diversos povos rurais, abordando as questões ambientais que os afetam, tais como disponibilidade, acesso, uso, qualidade e degradação dos recursos naturais. Além de contar com essas fontes, a Sociologia Ambiental dos anos 1970 recebeu contribuições da Antropologia Cultural, especialmente de sua vertente ecológica, bem como de outras áreas do conhecimento que passaram a se interessar por temas transversais associados à problemática ambiental.
Os enfoques da Sociologia Ambiental são diversos, em função da complexidade que implica uma conceituação abrangente sobre o meio ambiente e a maneira como as pessoas o representam. Buttel (2000) conceitua meio ambiente como sendo as bases físicas e materiais de toda a vida, incluindo terra, ar e água. Contudo, a Sociologia Ambiental também pode abordar as questões relativas ao meio ambiente no plano estritamente simbólico, focalizando não somente as condições ambientais de modo concreto, mas também como as pessoas interpretam e reagem a essas condições.

Há uma série de questões convergentes e divergentes na Sociologia Ambiental no que se refere às teorias sociológicas e ao meio ambiente. As principais convergências estão relacionadas às abordagens sobre $\mathrm{o}$ meio ambiente que assinalam que há uma significativa interação deste com os sistemas sociais e vice-versa. Desta forma, é reconhecido que as estruturas sociais modificam significativamente o ambiente natural e que, ao mesmo tempo, as condições ambientais constrangem a natureza e condicionam os processos de organização social. Conforme analisam Lima e Portilho (2001), a maioria dos sociólogos ambientais parece concordar que as sociedades tendem a persistir na agressão ao meio ambiente (apesar dos sinais de esgotamento que têm sido emitidos), pois as pessoas preferem ignorar problemas ambientais a se readaptar a novos constrangimentos. Concordam também que os fenômenos ambientais estão se tornando foco de antagonismos, conflitos e lutas políticas e que isso afeta grupos e interesses sociais de forma diferenciada.

As principais divergências estão relacionadas às diferentes abordagens teóricas que caracterizam a sociologia e que são encontradas também no interior da Sociologia Ambiental. Mesmo havendo crenças comuns sobre a relação entre sociedade e meio ambiente, há uma diversidade de perspectivas que tendem a se desenvolver no interior da Sociologia Ambiental. Por isto, as diferenças são inevitáveis quando se trata de abordar as consequências da poluição ou da exploração dos recursos hídricos, por exemplo. Entretanto, a identificação e a classificação dos diferentes paradigmas que competem no interior da teoria sociológica em geral constituem também um objeto de reflexão e de interesse da Sociologia Ambiental. 


\section{Construcionismo social: tendência analítica da Sociologia Ambiental}

Dois fatores interligados têm contribuído para as tendências analíticas da Sociologia Ambiental. O primeiro está relacionado à expansão do seu campo empírico em direção a três áreas de investigação: a Sociologia da Ciência, a Sociologia dos Riscos e a Sociologia dos Novos Movimentos Sociais. O segundo fator é que diversos teóricos sociais contemporâneos passaram a dar importância à perspectiva ecológica e às relações socioambientais. Seguindo essas tendências, é interessante destacar as linhas de estudos que procuram se articular com a Sociologia Ambiental, como a Sociologia dos Riscos, por exemplo, através de interpretações construcionistas. A relevância desta perspectiva, na qual situamos este artigo, está na importância que confere ao papel que a cultura e a ciência desempenham nas relações entre a sociedade e o meio ambiente. A perspectiva construcionista na Sociologia Ambiental tem como preocupação entender o modo como os problemas ambientais são definidos, articulados e acionados pelos atores sociais.

Para o estudo da perspectiva construcionista, tomo como referência a obra de John Hannigan (1995), que a apresenta como sendo também uma ferramenta para se estudar os processos de construção social de problemas ambientais. Segundo este autor, enquanto a maior parte das abordagens sobre meio ambiente apresenta a crise ambiental como produto de fatores de dimensão exógena, como o perigo das novas tecnologias, por exemplo, sua análise propõe um enfoque centrado nos processos sociais, políticos e culturais, onde as condições ambientais são definidas como sendo de riscos inaceitáveis e, portanto, passíveis de conflito. Ou seja, nesta perspectiva os problemas ambientais não resultam de condições objetivamente dadas, que poderiam ser evidenciadas apenas a partir das estimativas dos peritos, mas são antes socialmente construídos por meio de debates e negociações no espaço público, com a participação de leigos, inclusive. Além disso, considera-se que o próprio debate sobre determinadas questões ambientais, mesmo sob o ponto de vista científico, revela haver mais incertezas e contradições, inclusive com convicções irreconciliáveis, do que certezas, tanto nas estimativas como nas soluções propostas. Contudo, isto não significa que na abordagem construtivista haja uma negação da realidade objetiva dos problemas e dos riscos ambientais, ou da independência dos fatores causais da natureza sobre eles. Mas a legitimidade, a relevância e a prioridade atribuídas a estes problemas dependem da atuação de diversos agentes sociais. $\mathrm{Na}$ abordagem construcionista, as análises das agendas e das políticas ambientais são compreendidas como produtos finais de um processo social dinâmico de definições, negociações e legitimações.

Hannigan (1995, p. 40-51) expõe um interessante esquema, envolvendo três tarefas, para a análise do processo de construção social de um problema ambiental. A primeira tarefa é a montagem de uma reivindicação ambiental, que deve partir da descoberta inicial e elaboração ainda incipiente de um problema. Nesta fase é necessário: nomear o problema, distinguir de outros similares, determinar as bases científicas, técnicas, morais e legais da reivindicação, e atribuir quem é responsável por tomar ações para solucioná-lo. Na pesquisa sobre as origens da reivindicação é importante para o pesquisador saber de onde vem a reivindicação, quem a detém ou a administra, quais os interesses econômicos e políticos que os produtores da reivindicação representam e que tipo de recursos eles trazem para o processo de produção da reivindicação. Uma segunda tarefa no processo de construção de um problema ambiental é a apresentação da reivindicação. Uma reivindicação ambiental precisa tanto chamar a atenção como também se legitimar. Há diversos modos de se chamar a atenção, que envolvem desde o uso de gráficos até a exploração de imagens fortes relacionadas a acidentes ambientais, por exemplo. Também é possível provocar a emergência de uma nova questão ambiental por meio de um evento, quando: 1) provoca a atenção da mídia, 2) envolve algum setor do Estado; 3 ) demanda decisão governamental; 4) não se apresenta ao público como sendo uma extravagância; 5) diz respeito ao interesse pessoal de um número significativo de pessoas. Mas chamar a atenção não é suficiente para se obter uma nova questão ambiental. Para isso, um problema ambiental emergente deve ser legitimado em múltiplas arenas: a mídia, o governo, a ciência e o público.

Ainda assim, mesmo quando um problema ambiental é legitimado não significa que entrará na agenda pública. Diversos fatores podem contribuir para que 
uma questão ambiental seja esquecida, principalmente quando exige alocação de recursos econômicos. A implementação de uma proposição ambiental requer assim uma terceira condição, que é a disputa política, não somente para obter a sua regulamentação no campo legal, mas também para tornar efetiva a sua legislação correspondente. Tal condição sugere que, para uma proposta legislativa obter apoio, deve satisfazer alguns critérios: os legisladores devem ser convencidos que a proposta é viável e compatível com os seus valores; ou seja, para ter sucesso na arena política, uma reivindicação ambiental precisa combinar uma série de fatores, especialmente conhecimento e oportunidade. Hannigan (1995, p. 52-56) apresenta ainda outros fatores necessários para que a construção de um problema ambiental tenha sucesso: 1) deve haver uma autoridade científica para validar as reivindicações; 2) é importante a existência de popularizadores que transformam os conhecimentos técnicos e científicos em reivindicações ambientais num sentido proativo; 3 ) a mídia deve projetá-lo como algo novo e importante; 4) deve ser dramatizado em termos simbólicos e visuais; 5) os incentivos econômicos devem ser visíveis para se tornarem ações positivas.

Recentemente, a análise social dos riscos passou a ocupar um lugar central na teoria social. Dois dos mais influentes teóricos sociais contemporâneos - Anthony Giddens e Ulrich Beck - contribuíram decisivamente para essa centralidade ao considerarem os riscos, em especial os ambientais e tecnológicos, como chaves para entender as características, os limites e as transformações da sociedade moderna. Discutindo a complexidade dos riscos ambientais, esses autores lançaram nova luz sobre questões referentes aos conflitos sociais, às relações entre leigos e peritos, ao papel da ciência e às formas de fazer e definir a política. Apesar de a temática dos riscos não ser nova nas Ciências Sociais, as análises sobre ela sempre se mantiveram como uma área mais restrita de estudo, com ênfase decisiva em sua carga cultural e social. Nesse sentido, também contrariamente à prática das análises técnicas dos riscos, que isolam a opinião individual, as análises provenientes da Sociologia Ambiental não se perguntam sobre as crenças ou opiniões particulares dos indivíduos, mas sobre as teorias, os valores e os princípios que organizam seu mundo, construído e compartilhado socialmente.
Uma das primeiras críticas às análises técnicas sobre riscos, e marco inicial para uma abordagem cultural, foi desenvolvida a partir dos estudos de Mary Douglas (1966, apud GUIVANT, 1998). Esta antropóloga estabeleceu as bases do que passou a ser identificado como a teoria cultural dos riscos, segundo a qual as pessoas são organizadoras ativas de suas percepções, impondo seus próprios significados aos fenômenos. Posteriormente, Douglas e Wildavsky (1994, apud GUIVANT, 1998) trouxeram o tema dos riscos para o campo do debate político e moral e, nessa abordagem, a seleção dos riscos relevantes, nem sempre com evidência científica, teria papel esclarecedor pelo fato de a escolha geralmente corresponder a fatores culturais e sociais, ao invés de reagir diretamente a fenômenos naturais. A compreensão estaria no fato de que, na estimação desses riscos, ninguém pode dizer que é um perito.

Ainda que nos tenhamos beneficiado com os avanços científicos e tecnológicos, ao abrirem-se novas áreas de conhecimento, também aumenta a distância entre o que se conhece e o que seria desejável conhecer. Desta forma, a partir desta perspectiva, temos que lidar com conhecimentos que são incertos, aspectos que a perspectiva técnica sobre os riscos não considera ao intelectualizar os processos decisórios e enfatizar os impedimentos dos leigos, classificados como irracionais. Nesse cenário, onde há divergências significativas entre os peritos sobre quais são os métodos mais apropriados para estimar os riscos, assim como sobre quais são as margens desejáveis de segurança, valores comuns levam a medos comuns. As pessoas selecionam determinados riscos como relevantes segundo o papel que estes possam ter no reforço da solidariedade social das instituições das quais elas participam. A atenção que as pessoas dão a determinados riscos em lugar de outros seria parte de um processo sociocultural, que dificilmente tem uma relação direta com o caráter objetivo dos riscos.

Beck e Giddens transformaram substancialmente o debate sobre os riscos ao apresentá-los como centrais para entender a sociedade contemporânea. Ainda que reconheçam que sempre houve riscos, consideram que os atuais se tornaram de natureza objetivamente diferenciada. Para ambos, a sociedade contemporânea caracteriza-se pela radicalização dos princípios que orientam o processo de modernização industrial, o que marcaria a 
passagem da sociedade moderna para a sociedade da alta modernidade, conforme Giddens (1997), ou para a modernização reflexiva e para a sociedade de risco, segundo Beck (1997). Para esses sociólogos, ainda que com ambiguidades na definição dos riscos como construção social e cognitiva, as sociedades pós-industriais, ao contrário das sociedades industriais, enfrentam riscos ambientais e tecnológicos que não são meros efeitos colaterais do progresso, mas antes riscos substancialmente diferentes no que tange às fontes causadoras e à abrangência de seus efeitos. Essas transformações não são processadas de forma intencional e política, mas são o resultado das forças desta mesma sociedade. O progresso gerado pelo desenvolvimento da ciência e da tecnologia passa a ser considerado como a fonte potencial de autodestruição, a partir do qual se produzem novos riscos, difíceis de serem percebidos, cujas consequências são desconhecidas em longo prazo e não podem ser avaliadas com precisão.

A teoria da sociedade de risco tem como eixo a interpretação das formas pelas quais se interconectam processos que afetam os estatutos da ciência e da política. Para Beck (1997), a sociedade passou a ser um laboratório aberto, fora de controle, e as consequências deste processo levam a uma redefinição da forma e dos espaços de fazer política. O que era considerado uma esfera privada, de responsabilidade e criatividade científicas, passa a ser objeto de debate do que denomina de subpolítica. Nesse sentido, a esfera da subpolítica distingue-se da política oficial por envolver diversos atores sociais que passam a participar do debate público não apenas como agentes coletivos, mas também como indivíduos. O conceito de subpolítica define, portanto, uma situação em que atores externos ao sistema político oficial participam do planejamento social, moldando a sociedade de baixo para cima. O fato é que as instituições que amparam essa nova forma de atuação devem estar preparadas para delegar poder (BECK, 1997), pois a aplicação dessa formulação gera ainda algumas dúvidas a respeito de sua operacionalização política.

Nesse ponto, Giddens (1997, p. 109) assume um tom menos dramático na sua análise, além de manter um diálogo mais aberto e frequente com a teoria social. Segundo este autor, em uma sociedade destradicionalizada e que problematiza o futuro, a noção de risco é chave: viver no universo da alta modernidade é viver num ambiente de opções e riscos, concomitantemente, inevitáveis de um sistema orientado para o domínio da natureza e construção reflexiva da história. Sua análise abrange as transformações que caracterizam o período da alta modernidade, a separação do espaço e do tempo, a pulverização das relações sociais e o reordenamento reflexivo da ordem social, tanto no plano macrossocial como também, e fundamentalmente, na esfera mais íntima das pessoas em seu cotidiano.

Ao refletir sobre os riscos da alta modernidade, os autores esclarecem que não estão propondo que estes sejam necessariamente sempre maiores que os do passado. Na baixa modernidade, os riscos dominantes eram externos, ao atingir os indivíduos por vezes de forma inesperada, mas também podendo acontecer regularmente, permitindo que fossem calculados para que as populações pudessem se proteger. A especificidade dos riscos da alta modernidade é que seriam fenômenos novos, artificialmente manufaturados, ocasionados pelo próprio desenvolvimento científico e tecnológico, característico desta época, que podem provocar grandes consequências. Ou seja, quando nos apercebemos do alcance de tais riscos, pode ser tarde para se evitar as consequências.

Para Giddens (1991, 1997), a sociedade de risco é uma sociedade altamente preocupada com o futuro e a segurança. Na "cultura do risco", a ciência está desencantada e a certeza de seu conhecimento parece minada. Isso faz com que, nas decisões cotidianas, os indivíduos se reapropriem do conhecimento perito, sendo esse transformado pelos leigos tanto nos espaços da intimidade como nos espaços políticos. Numa sociedade destradicionalizada, como a da alta modernidade, a tradição não teria sido substituída pela certeza científica, mas pela dúvida radical. Estas transformações individuais vinculam-se a transformações globais, onde a possibilidade e a necessidade de escolha sobre nossa biografia far-se-iam acompanhar de um descrédito acerca do conhecimento dos peritos, permanentemente sob revisão e debate. Este processo de autoconstrução biográfica, distante das influências da tradição - e de reapropriação e reinterpretação do conhecimento perito - é denominado de reflexividade.

Beck (1997) e Giddens (1991, 1997) aproximam-se da abordagem cultural dos riscos ao considerarem que as fórmulas científicas para a estimação dos riscos 
ambientais levam implícitas definições sociais, culturais e políticas, envolvendo interesses de diversos atores sociais. Desta maneira, questões como o que é aceitável em termos de risco ambiental estão impregnadas de valores; assim, face ao peso dos julgamentos de valor envolvidos, os peritos perdem seu papel específico na delimitação dos riscos. Ambos compartilham com a crítica à dicotomia entre um conhecimento perito que "determina" os riscos e uma população leiga que os "percebe". Nesse espectro de pós-modernidade, lidar com os riscos leva a uma redefinição do que se entende por política, diferente da que caracterizava as estratégias da sociedade de classes na primeira fase da modernidade. A sociedade de risco implica pensar toda a agenda política porque pressupõe uma reorientação de valores e das estratégias para atingi-los.

Ainda que a política de emancipação continue sendo importante, é no plano do que Giddens (1997) denomina de "política da vida" que se discute como devemos viver em um mundo de escolhas e decisões permanentes sobre o que no passado era visto como natural. Em sua análise, estaríamos atravessando um período no qual, pela primeira vez, existiriam condições para a emergência de valores universais (responsabilidade por gerações futuras, por exemplo) dentro de uma ética de responsabilidade tanto individual quanto coletiva. $\mathrm{O}$ movimento ambientalista faz parte dessa política da vida, junto com práticas em outras áreas políticas, como as econômicas e de trabalho. Contudo, o destaque político que as questões ambientais têm conquistado nos últimos anos é relacionado com um acúmulo de evidências sobre as consequências de práticas humanas consideradas predatórias.

Por outro lado, as alternativas de Beck são menos difusas, mais normativas e mantêm no eixo político central as questões de risco. $\mathrm{O}$ autor identifica duas fases da sociedade de risco, sendo que a primeira corresponde à transição da sociedade industrial à sociedade de risco, processada de forma impremeditada: não se trata de uma opção, mas de uma dinâmica de radicalização da modernidade, a qual passa a se confrontar com seus próprios efeitos e perigos, que não podem ser controlados ou assimilados segundo os parâmetros da sociedade industrial. Esse processo é denominado por Beck como de "modernização reflexiva". Os riscos da modernidade ainda são gerados sem se tornarem assunto público ou o centro de conflitos políticos.

Na segunda fase, mais propícia a novas estratégias políticas, emerge um quadro diferente, com algumas das consequências da modernidade industrial sendo questionadas política e socialmente por organizações de interesse ambiental e pelo sistema jurídico e político. Aqui, o movimento ambientalista não necessariamente se constitui como um sujeito privilegiado, porque falaria em nome de uma natureza que não existe mais, que seria por sua vez pressuposta como parte do modelo da sociedade que se quer seguir. $\mathrm{O}$ que este movimento não consegue é ver a independência entre os processos de destruição e o nível de protesto político, que é mediado simbólica e culturalmente. Não foi, portanto, nem a evidência do dano nem o reconhecimento científico que geraram as ações subpolíticas dos ambientalistas locais, mas sim suas idiossincrasias socioambientais e seus valores culturais.

Um aspecto fundamental que influenciaria subjetivamente o reconhecimento dos danos ambientais como relevantes e significativos é justamente a percepção da disponibilidade de alternativas. Quando as pessoas se encontram em situações nas quais as alternativas são difíceis de visualizar, tendem a negar a sua condição de atingidos. Por isso, nem sempre os protestos emergem entre os mais ameaçados, mas entre setores de classe média, com suas percepções sobre saúde, segurança e lazer. Alguns destes setores podem se sentir ameaçados de perder o bem-estar conseguido. A partir daí, podem apresentar sistematicamente a questão ambiental como central no debate social contemporâneo, tornando-a dependente de normas legais debatidas e aprovadas a partir de acordos negociados entre diversos atores envolvidos.

Por fim, para ambos os teóricos, é inviável procurar resolver problemas relacionados aos riscos manufaturados com mais modernidade ou com conhecimentos científicos e tecnológicos equivalentes aos que os provocaram. Há elementos políticos irredutíveis presentes nas decisões sobre como lidar com os riscos e estes devem ser discutidos nesse plano, explicitando-se os valores culturais e sociais envolvidos de modo a redefinir os padrões de produção do conhecimento científico, bem como a atuação dos peritos. 


\section{Mudanças institucionais: a subpolítica dos ambientalistas pirajuenses}

A história do município de Piraju-SP (Figura 1) se confunde com a história do desenvolvimento da matriz hidroenergética nacional. Banhada pelo rio Paranapanema e cortada por outros tributários, o aproveitamento de seu potencial energético teve início já na primeira década do século passado. Em 1905, foi inaugurada a luz elétrica municipal a partir da construção da Usina Hidroelétrica Monte Alegre, distante cinco quilômetros do centro da cidade. Posteriormente, para atender a uma economia cafeeira em expansão, em 1913, começou a funcionar a Usina Hidroelétrica Boa Vista, fornecendo energia inclusive para uma linha de bonde, com 26 quilômetros de extensão, entre o ramal da Estrada de Ferro Sorocabana e o município de Sarutaiá (SP), passando pelas ruas de Piraju. Em 1937, foi concluída a Usina Hidroelétrica Paranapanema, um projeto de grande porte para a época. Sua barragem encontrava-se praticamente dentro da cidade, num trecho do rio Paranapanema que separava a Vila Tibiriçá da área central da cidade. Na década de 1960, foi a vez da construção da Usina Hidroelétrica Jurumirim.

Desde a inauguração da Usina Paranapanema e, posteriormente, da Usina Jurumirim, os habitantes de Piraju desenvolveram uma nova relação com os seus recursos hídricos. Dada a relativa calma das águas represadas, os pirajuenses passaram a desfrutar de áreas de lazer

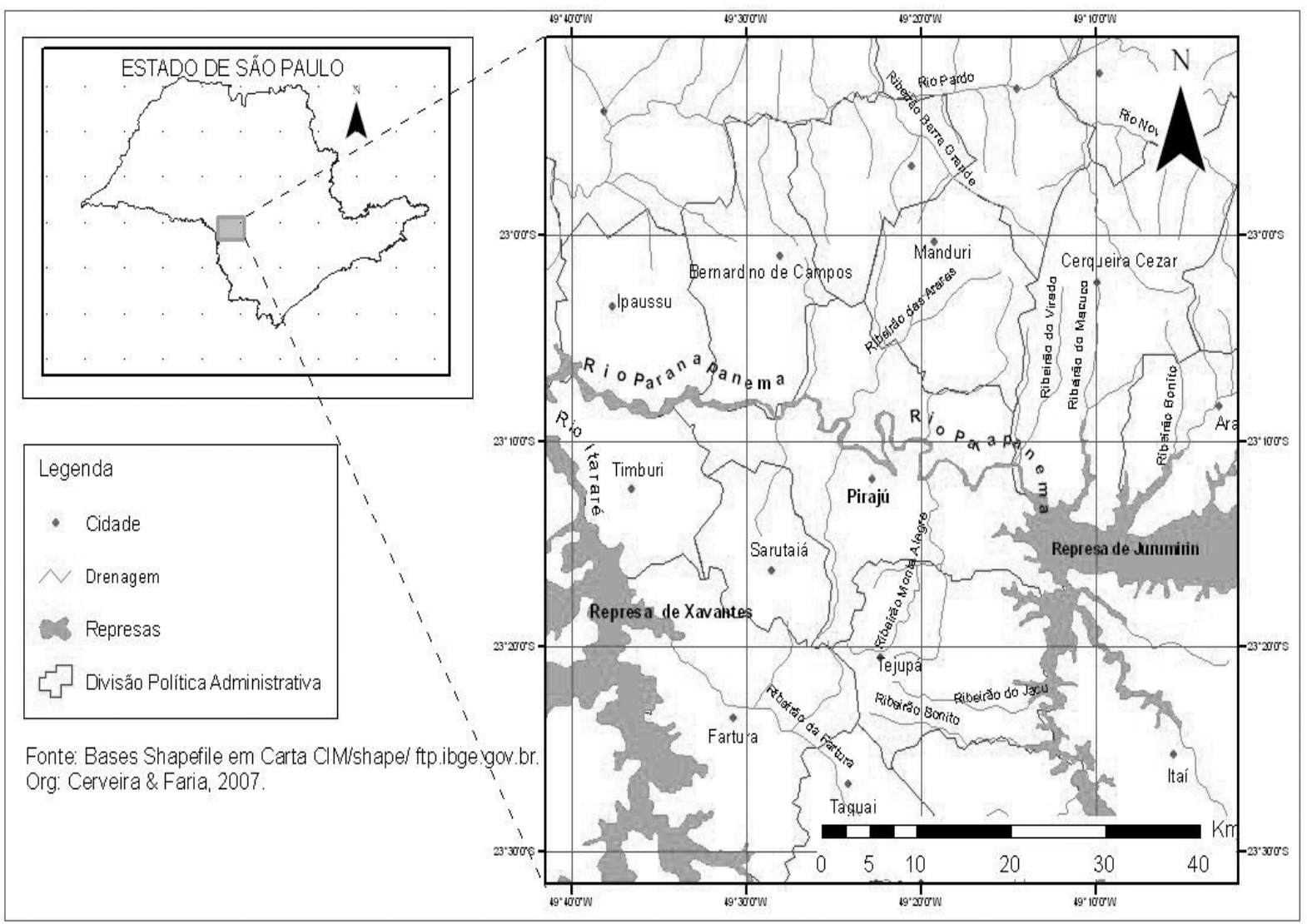

FIGURA 1 - Localização do município de Piraju (SP).

FONTE: CERVEIRA FILHO (2007) 
até então inexistentes. Esse fator, associado a fenômenos sociais mais abrangentes, interagiram para a construção de uma consciência ambiental de preservação do rio Paranapanema. Mudanças de caráter global fundiam-se às transformações, configurando-se em traços que são visíveis na formação de uma percepção ambiental, cristalizada no ideário de alguns atores sociais locais. A partir dos anos 1980, alguns desses atores começaram a articular demandas ambientais, em especial de preservação dos espaços de lazer que conheceram e desfrutaram na infância e na adolescência, pois, como classe média, tiveram a oportunidade de cursar faculdades em outras cidades, contudo mantendo fortes vínculos com a cidade, como uma rede de informações ambientais.

Alguns desses atores rememoram um fato considerado paradigmático na mudança de postura da sociedade para com a questão ambiental, especificamente as questões hidroelétricas, ocorrido entre o final dos anos 1980 e início dos anos 1990. Na época, a Companhia Brasileira de Alumínio (CBA) planejava a construção da usina Piraju por meios de um projeto que previa o desvio do rio Paranapanema, o que reduziria a sua vazão no trecho urbano de $300 \mathrm{~m}^{3} / \mathrm{s}$ para $10 \mathrm{~m}^{3} / \mathrm{s}$. Se essa obra fosse levada a cabo, havia o risco de deterioração da qualidade das águas no local e o temor de surgimento de algumas doenças, entre elas a leishmaniose. A partir dessa percepção, esse grupo realizou pesquisa na Secretaria Estadual do Meio Ambiente do Estado de São Paulo (SMA) e descobriu, por exemplo, que o Estudo de Impacto Ambiental (EIA) (BRASIL, 1986) da Usina Piraju já havia sido realizado e encontrava-se com parecer favorável. Nesse período, algumas mudanças institucionais no âmbito federal já estavam em andamento e, a partir do conhecimento dessas mudanças, passaram a denunciar a condução ilegal do processo, argumentando sobre a obrigatoriedade de realização de audiência pública para a obtenção da licença ambiental.

Convenceram a mídia, obtendo apoio para a divulgação dos eventos que programavam, e em poucos dias já haviam conseguido influenciar a Câmara de Vereadores, que realizou uma série de sessões destinadas a discutir o projeto e a envolver a comunidade. Em um crescente, o debate recebeu a adesão da Maçonaria e, posteriormente, da Organização Pirajuense de Educação e Cultura (OPEC). Por último, a Delegacia Regional de Ensino passou a promover palestras nas escolas da rede pública. Na cidade, em poucos dias, partes do EIA constantes no processo estavam popularizadas e a partir daí os questionamentos sobre a construção da Usina Piraju passaram a ser, também, de envergadura política. O resultado desse conflito foi a alteração do projeto por parte da CBA, reconfigurando-o a um modelo tradicional que foi concluído em 2002, após intensa negociação com a comunidade. De certa forma, a presença de outros atores sociais junto a essas demandas, agremiadas a partir de novas alianças políticas, deu maior visibilidade à condução das questões socioambientais provenientes da construção de hidroelétricas no município. Nesse ponto, observa-se que a necessidade de mobilização da comunidade esteve baseada na descrença quanto à possibilidade de interferência de modo individual no processo de licenciamento ambiental.

Contudo, nas décadas de 1980 e 1990, institucionalmente, amadureceram novas formas de gestão dos recursos hídricos, e entre elas observa-se a estruturação de um marco jurídico regulatório que previu maior participação social nos processos decisórios. No âmbito federal, foram sancionados a Lei $n^{\circ}$ 9.433/97 (BRASIL, 1997), que instituiu o Plano Nacional de Recursos Hídricos, e o Decreto no 2.162/98 (BRASIL, 1997), que criou o Conselho Nacional de Recursos Hídricos. No plano estadual, foi sancionada a Lei $\mathrm{n}^{\circ} 7.663 / 91$ (SÃO PAULO, 1991), que instituiu a Política Estadual de Recursos Hídricos e criou o Sistema Integrado de Gerenciamento de Recursos Hídricos. Também, a partir desse modelo de gestão, a Agência Nacional de Águas (ANA) (BRASIL, 2000) passou a ser responsável pela emissão de outorgas de uso dos recursos hídricos, bem como de concessões preliminares para uso, como as reservas de disponibilidade hídrica. Alguns atores locais rapidamente compreenderam as mudanças que estavam em curso, exigindo maior comunicação por parte do poder público sobre os eventos socioambientais que se espreitavam para o município. No limite, desejavam, a partir da década de 1990, participar das decisões que seriam tomadas envolvendo a construção de usinas hidroelétricas no município, assumindo mesmo um papel na condução das questões socioambientais. Sob a ótica de Beck (1997), esses atores tenderam a se tornar independentes dos processos políticos tradicionais, partindo 
para um tipo de ação propícia da alta modernidade, a subpolítica.

Como contraponto a esses interesses, e antes mesmo da conclusão da Usina Piraju, a CBA deu início aos trâmites legais e burocráticos para a construção de outra usina hidroelétrica no município. Ainda no primeiro semestre de 2001, a empresa entrou com pedido na SMA para análise de EIA, e, no segundo semestre daquele ano, solicitou à ANA consulta sobre procedimento de outorga de direitos de uso de recursos hídricos para o projeto denominado Piraju II. Esse fato mobilizou um grupo de ambientalistas locais, que empreenderam demandas contra o andamento do projeto. Naquele momento, divulgaram relatório negativo sobre o andamento da construção da Usina Piraju, fato que desgastou a imagem da empresa na comunidade. A geração de empregos prometida passou a ser questionada e espalharam-se notícias sobre soterramento de material arqueológico encontrado no local das obras. Também nesse momento, o Sindicato Rural de Piraju passou a pressionar o Executivo a auxiliá-lo na resolução de uma pendência agrária envolvendo a CBA, já que alguns agricultores encontravam-se interpelados judicialmente pela empresa por não aceitarem os valores ofertados para a desapropriação de áreas a serem alagadas.

Entretanto, mesmo diante desses eventos, a CBA entrou com processo junto à Agência Nacional de Energia Elétrica (ANEEL) sem anúncio público e, dando continuidade aos seus planos, solicitou aprovação da planta básica da Piraju II, a partir do aproveitamento hidrelétrico Araras, o que representaria o alagamento do que era considerado o último trecho de curso natural do rio Paranapanema. Diante dessa ameaça, esse grupo voltou a se articular no intuito de proteger o que era considerado um patrimônio natural e cultural do município. Sentindo o bom momento de aproximação com as forças conservadoras, naquilo que Giddens (1997) vai denominar de "novos alinhamentos políticos", alguns ambientalistas propuseram ao Executivo, com a aprovação dos líderes rurais, a criação de um parque municipal exatamente no local que a empresa intencionava a nova usina, convencendo-os através de argumento bastante simples: caso o projeto Piraju II fosse aprovado, a presença de um parque no local contribuiria para que a Secretaria Estadual do Meio Ambiente indeferisse o pedido de licença ambiental.
Alguns dias depois, o projeto de lei que criava o parque foi levado ao Prefeito, que, em regime de urgência, o remeteu à Câmara de Vereadores, onde foi aprovado por unanimidade, dando origem à lei $\mathrm{n}^{\mathrm{o}} 2.634$, de 26 de junho de 2002, que criou o Parque Natural Municipal do Dourado (PIRAJU, 2002b). A criação desse parque pode ser considerada como o primeiro instituto jurídico construído socialmente na tentativa de se obstruir o projeto Piraju II. Posteriormente, o Conselho Municipal do Meio Ambiente e Patrimônio Cultural (CMMAPC) baixou a Resolução $n^{\circ}$ 01/2002 (PIRAJU, 2004), que aprovou o tombamento do trecho de sete quilômetros de calha natural do rio Paranapanema como patrimônio ambiental do município, considerado como dotado de elementos de valor cênico, paisagístico e cultural. Estava construído o segundo instituto jurídico local.

Em julho de 2002 o reservatório da Usina Piraju começou a ser formado. Ao passo que o nível das águas superava o máximo maximorum, ampliava-se a percepção local da CBA como empresa ambientalmente irresponsável, sendo acusada de erro técnico no cálculo da área alagada. Foram divulgadas diversas fotos na cidade com imagens de árvores submersas e início de processos erosivos na foz de alguns tributários. A dramatização imposta por essas imagens sensibilizou até mesmo outros atores sociais que estavam insensíveis à questão. Em seguida, a Câmara de Vereadores iniciou um período de debates que se estendeu por algumas semanas, culminando, em 12 de setembro de 2002, na aprovação da Lei ${ }^{\circ} 2.654$, que fixou um interregno de vinte anos entre o término de construção de uma usina hidroelétrica no município e o início de construção de outra, com o objetivo de possibilitar a análise do impacto da obra, assim como garantir às gerações futuras meios de decidir sobre a forma de sua preservação (PIRAJU, 2002c). Estava criado o terceiro instituto jurídico construído com o objetivo de obstruir a construção de novas usinas hidroelétricas na localidade. A partir desse conjunto jurídico, a SMA realizou consulta ao executivo para, em seguida, indeferir ambientalmente o projeto Piraju II.

A partir de 2003, o conflito tomou o rumo dos bastidores. Mesmo diante desse conjunto jurídico local, somado ao indeferimento estadual, a empresa não engavetou o projeto. Aproveitando-se dos labirintos burocráticos e da baixa comunicação entre a SMA e as 
agências ANA e ANEEL, o processo de solicitação de outorga preventiva tramitou junto à ANA e culminou na Resolução ANA nº 460/2003 (BRASIL, 2003), que declarou reservada a disponibilidade hídrica com a finalidade de possibilitar o aproveitamento hidrelétrico Piraju II. Nesse ponto, é interessante observar que, no inciso IV do artigo $3^{\circ}$, esta Resolução infere que, por se caracterizar como outorga preventiva, a mesma poderia ser suspensa em caso de indeferimento de Licença Ambiental, fato que já estava consolidado. Mesmo assim, a ANEEL, por meio da Resolução ANEEL nº 227/2005 (BRASIL, 2005), autorizou a construção do empreendimento, para espanto da comunidade.

Concomitantemente ao andamento destes processos, a cidade debatia o seu modelo ideal de plano diretor, quando alguns ambientalistas puderam exercer considerável influência na formatação e na sanção da Lei $\mathrm{n}^{\circ} 2.792$ (Plano Diretor) (PIRAJU, 2004). Se nos artigos iniciais esta Lei apresentou as coordenadas para um planejamento cuidadoso e refletido para a comunidade, conforme se avança no texto percebem-se diversas objeções às questões hidrelétricas. Observa-se nesse documento, por exemplo, a quantidade de vezes em que o trecho do rio à jusante da Usina Paranapanema aparece como "patrimônio cultural". Formatava-se assim o quarto instituto jurídico-reflexivo local.

Nesse período, novas informações sobre problemas socioambientais que estavam ocorrendo na bacia de inundação da Usina Piraju foram popularizados na cidade e contribuíram para generalizado mal-estar entre munícipes. A indignação de novos atores sociais contribuiu para o surgimento de uma percepção local de que, moralmente, algo deveria ser feito. Nesse sentido, em setembro de 2004, a Ordem dos Advogados do Brasil (OAB), por meio de sua $112^{\mathrm{a}}$ Subseção de Piraju, protocolou representação contra a CBA no Ministério Público Estadual (MPE) por intermédio da Promotoria de Justiça de Piraju. O texto que compôs a redação da referida representação apresenta profunda relação com a retórica ambientalista, o que corrobora nossa análise sobre as ações subpolíticas que estavam em andamento. A partir daí, o MPE acatou a representação e instaurou o Procedimento Preparatório de Inquérito Civil no 52/04 (SÃO PAULO, 2004).

No início de 2005, a Diretoria Regional do DEPRN designou um engenheiro agrônomo para realizar a visto- ria técnica no reservatório da Usina Piraju para verificação in loco do cumprimento das exigências ambientais constantes na Licença de Operação, em companhia de um técnico ambiental da CBA. O que o enviado do DEPRN encontrou nos locais foi transmitido ao MPE por meio do Ofício $n^{0} 38 / 05$, e o seu conteúdo deu conta de expor graves problemas ambientais em andamento. Posteriormente, a empresa recebeu notificação do MPE para responder os termos da representação e do laudo pericial. Esse documento também exigiu do empreendedor corrigir, de imediato, as irregularidades, sob pena de responsabilização civil pelos danos causados ao meio ambiente. Em 7 de junho de 2005, a CBA enviou resposta ao MPE, quando procurou responder sobre possíveis falhas no cumprimento das condicionantes exigidas pelo Departamento de Avaliação de Impacto Ambiental (DAIA) da SMA para a obtenção da Licença de Operação (SÃO PAULO, 2002).

Novamente, nesse período, os ambientalistas vinham reclamando do pouco interesse da edilidade na questão. Dessa maneira, foi-lhes organizado um evento que previu a apresentação de uma monografia defendida em um curso de Pedagogia da OPEC, que versava sobre a importância cultural do rio Paranapanema para a disciplina de Educação Ambiental na rede municipal. Depois desse evento, a Câmara de Vereadores se pronunciou diretamente ao MPE, solicitando informações sobre os problemas que vinham ocorrendo na área de influência da Usina Piraju. Novamente o MPE foi "incomodado" pelos ambientalistas, que a essa altura estavam refinados ao estilo subpolítico de agir, especializando-se em competir com o empreendedor pela via do conhecimento, desmonopolizando o papel dos peritos e provocando as instituições à ação. Nesse episódio, ficou claro que a tática desses atores foi a de provocar o MPE local através da mediação da Câmara de Vereadores.

Em outro espectro, nesses mesmos dias a mídia ampliou a sua estratégia de persuasão para conquistar negócios com a CBA. A expectativa para novos contratos de anúncios era grande, mas, na medida em que os negócios não foram fechados, a imprensa local se revezou na pressão junto ao grande grupo. Ao passo que a Folha de Piraju investiu em notícia sobre a importância das corredeiras do rio Paranapanema (FOLHA DE PIRAJU, 2005), O Observador foi mais agressivo 
ao publicar que a Vigilância Epidemiológica constatara trinta e três vezes mais casos de leishmaniose em Piraju para o período entre 2001 e 2003. Nessa reportagem, havia a indicação de que a construção da Usina Piraju teria contribuído significativamente para esse aumento (O OBSERVADOR, 2004). Posteriormente, o resultado da pressão parece ter surtido efeito, pois os noticiários locais foram inundados por notícias sobre a pujança da CBA e suas preocupações socioambientais.

Esse marketing foi percebido como estratégia do empreendedor para reconquistar aliados na comunidade. Como contraponto, novamente procuraram levar a disputa socioambiental para um terreno favorável ao estilo subpolítico: articularam reunião com o Ministério Público Federal (MPF) de Ourinhos (SP), quando convenceram o Procurador sobre as irregularidades das resoluções da ANA e da ANEEL. O alvo não era mais a empresa, mas sim as suas conquistas institucionais, consideradas ilegais, e, nesse âmbito, obtiveram do MPF o compromisso de notificação das agências para que atentassem ao indeferimento deliberado pela SMA. Contudo, nesse período, a mais importante conquista institucional se deu a partir de uma ação subpolítica exemplar: de posse dos documentos que embargavam a construção da Usina Piraju II, os ambientalistas articularam visita à Procuradoria-Geral da ANA, onde protocolaram Documento ANA $n^{\circ} 00000.007340 / 2006$, que originou o Processo ANA 02501.000641/2006. Em seguida, e até para surpresa do grupo, a ANA publicou a Resolução $\mathrm{n}^{\circ}$ 212, em 15 de maio de 2006, que declarou suspensos os efeitos da antiga resolução de outorga. Esse fato foi muito comemorado, pois solidificou a luta socioambiental pela via subpolítica, interpondo exigências legais e obstáculos institucionais no caminho do empreendedor.

\section{Considerações finais}

Não obstante a construção social dos problemas ambientais e das ações subpolíticas, a análise desse estudo de caso é concluída com as principais ações envolvendo as disputas ocorridas no primeiro semestre de 2007. Nesse período, o conflito se ampliou significativamente e as primeiras notícias demonstravam que a CBA novamente se articulava junto à municipalidade no sentido de destravar o arcabouço jurídico local por intermédio da renovada Câmara de Vereadores. Para o intento, o novo executivo e a CBA entenderam que, legalmente, o melhor caminho seria o da revisão do Plano Diretor Municipal, através da montagem de um Fórum Popular para apresentação de proposições que visassem à alteração de alguns artigos, principalmente aqueles que buscavam preservar o trecho de corredeiras do rio Paranapanema. Os ambientalistas sentiram que havia chegado o momento de testar socialmente suas formulações e articularam a presença de simpatizantes à causa durante a realização do Fórum.

Nesse espectro de enfrentamento, o debate foi tumultuado logo na primeira reunião, quando da leitura de uma proposta que previa a revogação do arcabouço regulatório protetor do rio, apresentada por uma associação de moradores de bairro altamente controlada pelo Executivo. Essa proposta foi contestada, inicialmente, por um membro da própria associação, que denunciou abertamente não ter conhecimento em que circunstâncias tal documento fora elaborado, causando mal-estar até entre os membros pró-usina que estavam presentes. Por se tratar-se de articulação escusa envolvendo a CBA, membros do Executivo e a associação de bairro, os ambientalistas partiram para um tipo de ação mais tradicional: dada a gravidade do fato, procuraram a Polícia Civil e registraram queixa de falsidade ideológica e formação de quadrilha. Alguns dias depois, o Fórum Popular rejeitou definitivamente a proposta para revogação daqueles institutos que protegiam o rio.

Finalizando, é cabido mencionar que esse episódio envolvendo a CBA revitalizou o debate ambiental na comunidade. No limite, um grupo de atores sociais identificados com a questão ambiental procurou evidenciar a maneira como a questão vinha sendo conduzida na comunidade, pois, em suas análises, seria impensável permitirem-se negociações com uma empresa ambientalmente insensível e que se comportava de maneira a buscar maior produção de energia escondendo os desastres impetrados ao ambiente onde atua. Não obstante esse constrangimento, a intenção da empresa, com a anuência da ANEEL, continua viva no município, apelando talvez para a tática da insistência, julgando que "água mole em pedra dura, tanto bate até que fura”. Entretanto, diante da reflexividade social intrínseca à sociedade de 
risco, e se depender do empenho e da versatilidade dos subpolíticos ambientalistas locais, o ditado popular, em tempos de reinvenção da política, poderá ser dito da seguinte maneira: "pedra mole em água dura, tanto fura até que não bate".

Com esse relato dos embates socioambientais ocorridos entre ambientalistas locais e a CBA nas diversas esferas políticas, encerramos esse artigo, cuja proposta foi analisar, por meio de uma exposição teórica e de um estudo de caso, a ótica da subpolítca proposta por Beck

\section{Referências}

ACSELRAD, H. et al. Conflitos ambientais no Brasil. Rio de Janeiro: Relume-Dumará, 2004.

ALONSO, A.; COSTA, V. Ciências Sociais e meio ambiente no Brasil: um balanço bibliográfico. Boletim Informativo Bibliográfico, n. 53, $1^{\circ}$ semestre 2002.

BECK, U. A reinvenção da política: rumo a uma teoria da modernização reflexiva. In: ; GIDDENS, A.; LASH, S. Modernização reflexiva: política, tradição e estética na ordem social moderna. São Paulo: Unesp, 1997.

BRASIL. Conselho Nacional de Meio Ambiente. Resolução Conama n. 01, de 23 de janeiro de 1986. Dispõe sobre a obrigatoriedade de realização de EIA/RIMA para obtenção de licença ambiental. Diário Oficial da União. Brasília, 17 de fevereiro de 1986.

Lei n. 9.427, de 26 de dezembro de 1996. Institui a Agência Nacional de Energia Elétrica. Diário Oficial da União. Brasília, 26 de dezembro de 1996.

. Lei n. 9.433, de 08 de janeiro de 1997. Institui a Política Nacional de Recursos Hídricos e cria o Sistema Nacional de Gerenciamento de Recursos Hídricos. Diário Oficial da União, Brasília, 09 de janeiro de 1997.

. Lei n. 9.984, de 17 de julho de 2000. Dispõe sobre a criação da Agência Nacional de Águas. Diário Oficial da União. Brasília, 18 de julho de 2000.

. Resolução ANA n. 460, de 18 de dezembro de 2003. Declara reservada, na seção do Rio Paranapanema, a disponibilidade hídrica com a finalidade de possibilitar o aproveitamento hidrelétrico Piraju II, no município de Piraju, Estado de São Paulo. Diário Oficial da União. Brasília, 24 de dezembro de
(1997). Pôde-se observar, ao longo do texto, a construção social do ambientalismo local e a habilidade subpolítica de um grupo ambientalista em identificar mudanças no marco jurídico e regulatório que permitiram uma atuação mais individualizada e de maior alcance. Em última análise, o grupo demonstrou que é possível participar do planejamento social, alterando planos e projetos de grandes grupos empresariais, mesmo estando fora do sistema político tradicional.

2003. Disponível em: <http://www.ana.gov.br/AcoesAdministrativas/Resolucs/resolucoes2003/460-2003.pdf $>$. Acesso em: 25/07/2005.

. Resolução Autorizativa n. 227, de 04 de julho de 2005. Autoriza a Companhia Brasileira de Alumínio a estabelecer-se como Produtor Independente de Energia, mediante a exploração do potencial hidráulico denominado PCH Piraju II, localizado no rio Paranapanema, Município de Piraju, Estado de São Paulo. Diário Oficial da União. Brasília, 04 de julho de 2005.

BUTTEL, F. Sociologia Ambiental, qualidade ambiental e qualidade de vida: algumas observações teóricas. In: HERCULANO, S. Qualidade de vida e riscos ambientais. Niterói: UFF, 2000.

CERVEIRA FILHO, J. L. F. Pós-modernidade e risco na Bacia Hidrográfica do Alto Paranapanema: uma análise da construção social da subpolítica ambiental no município de Piraju (SP). Tese (Doutorado) - UFSCAR. São Carlos, 2007.

FOLHA DE PIRAJU, 1971-2007.

GIDDENS, A. As consequências da modernidade. São Paulo: Unesp, 1991.

. A vida em uma sociedade pós-tradicional. In: BECK, U.; GIDDENS, A.; LASH, S. Modernização reflexiva: política, tradição e estética na ordem social moderna. São Paulo: Unesp, 1997.

GUIVANT, J. S. Trajetórias na análise dos riscos: da periferia ao centro da teoria social. Revista de Informações Bibliográficas, ANPOCS, n. 46, s/1, 1998.

HANNIGAN, J. A. Sociologia Ambiental: a formação de uma perspectiva. Lisboa: Inst. Piaget, 1995. 
LIMA, G. F. C.; PORTILHO, F. A Sociologia Ambiental no contexto acadêmico norte-americano: formação, dilemas e perspectivas. Teoria \& Sociedade, São Paulo, n. 7, 2001.

O OBSERVADOR, 1992-2007.

PIRAJU. Prefeitura Municipal. Lei n. 1.752, de 24 de julho de 1992. Dispõe sobre a criação do Conselho Municipal de Meio Ambiente e Patrimônio Cultural de Piraju. Departamento de Administração. Piraju, 26 de junho de 2002a.

Prefeitura Municipal. Lei n. 2.634, de 26 de junho de 2002. Cria o Parque Natural Municipal do Dourado e dá outras providências. Departamento de Administração. Piraju, 26 de junho de $2002 b$.

. Prefeitura Municipal. Lei n. 2.654, de 12 de setembro de 2002. Fixa o interregno de 20 anos para construção de usina hidrelétrica de iniciativa privada no território do Município de
Piraju e dá outras providências. Departamento de Administração. Piraju, 12 de setembro de 2002c.

. Prefeitura Municipal. Lei n. 2.792, de 08 de junho de 2004. Institui o Plano Diretor da Estância Turística de Piraju. Departamento de Administração. Piraju, 08 de junho de 2004.

SÃO PAULO. Lei n. 7.663, de 30 de dezembro de 1991. Estabelece normas de orientação à Política Estadual de Recursos Hídricos bem como ao Sistema Integrado de gerenciamento de recursos Hídricos. Diário Oficial do Estado de São Paulo. São Paulo, 31 de dezembro de 1991.

Secretaria do Meio Ambiente. Licença Ambiental de Operação n. 00104. Diário Oficial do Estado de São Paulo. São Paulo, 25 de julho de 2002.

. Ministério Público do Estado de São Paulo. Procedimento Preparatório de Inquérito Civil n. 52. Piraju: PJP/ MPE, 2004.

Recebido em 2 de junho de 2012. Aceito em 20 de julho de 2012 . Publicado em dezembro de 2012. 